\title{
Numerical Simulation of Static Stress-Strain Relationship and Failure Mode for Freeze-Thaw Concrete
}

\author{
Xiaolin Yang $\mathbb{D}^{1,2,3}$ Genhui Wang, ${ }^{2}$ Hongzhao $\mathrm{Li}^{1}{ }^{1}$ and Jiang Fan ${ }^{4}$ \\ ${ }^{1}$ School of Civil Engineering, Qinghai University, Xining, Qinghai, 810016, China \\ ${ }^{2}$ School of Civil Engineering, Lanzhou Jiaotong University, Lanzhou, Gansu, 730070, China \\ ${ }^{3}$ Qinhai Provincial Key Laboratory of Energy-saving Building Materials and Engineering Safety, Xining, Qinghai, 810016, China \\ ${ }^{4}$ Gansu Province Transportation Planning, Survey \& Design Institute Co., Ltd., Lanzhou, 730000, China \\ Correspondence should be addressed to Xiaolin Yang; xiaoliny@foxmail.com
}

Received 30 August 2019; Revised 8 February 2020; Accepted 15 May 2020; Published 2 June 2020

Academic Editor: Francesco Colangelo

Copyright $\odot 2020$ Xiaolin Yang et al. This is an open access article distributed under the Creative Commons Attribution License, which permits unrestricted use, distribution, and reproduction in any medium, provided the original work is properly cited.

\begin{abstract}
To analyze the causes of failure of cubic concrete test specimens under quasistatic axial compression, microtests and finite element numerical simulation of $\mathrm{C} 40$ cubic concrete test specimens were conducted without the freeze-thaw cycle and with 50 freeze-thaw cycles. Based on the analysis of the microstructure of concrete, the variation law of the full curve of stress and strain was analyzed by the uniaxial compression test and the splitting tensile test of concrete. The results show that freeze-thaw damage is mainly caused by the cyclic reciprocating stress of the micropore structure inside the concrete. The peak stress of concrete uniaxial compression and splitting tensile strength gradually decrease with the number of freeze-thaw cycles; the full stress-strain curve tends to shift downward and to the right. Finite element analysis shows that under the quasistatic uniaxial compression loading condition, the stress and strain fields in the test specimens are symmetrically distributed but nonuniform. The plastic deformation of the concrete weakens the nonuniformity of the stress distribution and is closer to the experimental failure morphology.
\end{abstract}

\section{Introduction}

Due to the cold weather and large temperature difference between day and night in the Qinghai-Tibet Plateau, concrete structures are likely to freeze at night and thaw due to solar radiation during the day. Freeze-thaw cycling conditions are a primary cause of durability deterioration of concrete structures in the regions with extreme temperature variations [1]. In cold climates, damage to concrete attributable to frost action (freezing and thawing cycles) is one of the major problems requiring heavy expenditures for the repair and replacement of structures [2]. The initial mechanical properties of concrete were adversely affected by the freezing-thawing cycle. Meanwhile, the pore structure and its physical properties were changed by the hydraulic pressure (due to an increase in the specific volume of water on freezing in large cavities) and osmotic pressure (due to salt concentration differences in the pore fluid) [3] during the freezing-thawing cycle.
Benefited from the progress of microtesting technology, many new techniques, including scanning electron microscopy (SEM) [4], computerized tomography (CT) [5], and X-ray diffraction analysis (XRD) [6], have been applied to the testing of concrete pore structure and the characterization of their components. Much research has been performed on the macroscopic characterization and $\mathrm{mi}-$ croscopic mechanism of the mechanical property degradation of concrete after freeze-thaw cycles. These studies focused on the decline of mechanical properties and microscopic characterization. Tian et al. [7] used CT and SEM techniques to study the erosion degradation of concrete under the coupling of freeze-thaw cycles and sulfate solution from a fine microscopic point of view. It was found that the mass loss of the concrete sample increases initially, then decreases slightly, and the trend increases rapidly at later stages; the uniaxial compressive strength increases and then decreases. Guo et al. [8] studied the variation of frost resistance of road concrete under different gas contents and 
water-cement ratios. The results show that the water-cement ratio has an important influence on the average pore diameter and concrete frost resistance. Yang et al. [9] conducted a series of experiments on concrete experiments on concrete specimen and determined the freeze-thaw-based damage variable. Jiang and Niu [10] analyzed the variation of peak stress, peak strain, and uniaxial compressive stressstrain curves of concrete under freezing and thawing conditions of sulfate solution. The results show that as the number of freeze-thaw cycles increases, the stress-strain curve gradually flattens and shifts to the right. Wang et al. [11] used scanning electron microscopy and the mercury intrusion method to study the uniaxial compressive stressstrain full curve and pore structure characteristics of shotcrete under freeze-thaw action. Duan et al. [12] researched unconfined and confined concrete after exposure to freezethaw cycles and established formulations for the main parameters, including compressive strength, peak strain, and elastic modulus, through regression analysis.

For the above research, experimental analysis on concrete exposed to freeze-thaw cycles is comprehensive. The constitutive relationship of concrete under freezing-thawing test conditions has been studied. However, the numerical simulation for concrete failure mode was seldom mentioned, based on constitutive relation obtained from experiment. For concrete subject to the cumulative effect of freezingthawing cycle, the mechanical properties were different from the initial state. Therefore, the slow freezing test standards [13] were adopted, and the numbers of freeze-thaw cycles of the concrete specimens were set as $0,25,50$, and 75 times. In this paper, the four full stress-strain curves for concrete subjected to different numbers of freeze-thaw cycles were chosen as the calibration data in the Concrete Damage Plasticity model. Through finite element analysis in ABAQUS, the equivalent plastic strain of freeze-thaw concrete was analyzed. Moreover, the strain and failure mode of concrete specimens under uniaxial compression were simulated. The constitutive model calibrated by experimental data can be used to analyze capacity of concrete structures in Qinghai-Tibet Plateau.

\section{Materials and Methods}

The superstructures of concrete bridges in the Qinghai-Tibet Plateau area mostly adopt C40 concrete. A recommended mix proportion of cement, water, sand, and stone is $1: 0.49$ : $1.55: 3.15$ [14]. A cubic specimen of $100 \times 100 \times 100 \mathrm{~mm}$ was poured for quasistatic compression and splitting tensile tests.

The slow freezing method specified in "Standard for Testing Method of Long-term Performance and Durability of Ordinary Concrete" was adopted in the freeze-thaw test of concrete [11]. Before freezing and thawing, the specimens were immersed in water for four days and then placed in a freezer at $-18^{\circ} \mathrm{C}$ for no less than four hours. After freezing, the melting time should have been no less than four hours when water at $20^{\circ} \mathrm{C}$ was added. During the freeze-thaw process, a thermocouple sensor was used to measure the

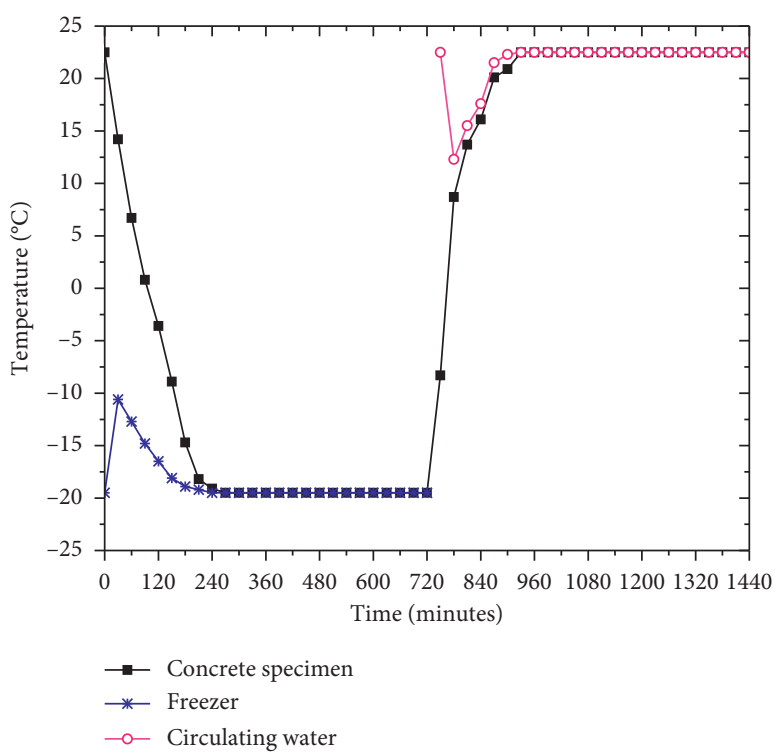

FIgURE 1: Temperature-time curve in a freeze-thaw cycle.

center temperature of the concrete test specimen (Figure 1) to ensure that it reached the freeze-thaw temperature.

High-resolution scanning electron microscopy (JSM$6610 \mathrm{LV}$ ) was used to analyze the micropore structure of the concrete after freeze-thaw cycles. The compression and splitting tensile tests of concrete cube specimens were based on the standard of the ordinary concrete mechanical property test method [15]. The stress-strain curves of concrete subjected to compression and splitting tension under different freeze-thaw cycles were determined by a HUT1000k microcomputer-controlled hydraulic universal testing machine manufactured by Shenzhen Wance Experimental Equipment Co., Ltd.

\section{Results and Discussion}

3.1. Micropore Structure Characteristics of Freeze-Thaw Concrete. The microstructure of concrete includes aggregate, hydrated cement paste, and an interface transition zone between cement paste and aggregate [2]. The microstructure of concrete is generally observed under a microscope. In this paper, the micromorphology of concrete after freeze-thaw cycles was observed by means of a high-resolution scanning electron microscope.

Figures 2(a)-2(d) show 500-fold scanning electron microscope binary images of PCAS analysis $[16,17]$. The results show that with the increase of freeze-thaw cycles, the microcracks and micropore fraction in concrete gradually increase from $2.74 \%$ (non-freeze-thaw cycles) to $6.7 \%(25$ freeze-thaw cycles), $8.96 \%$ (50 freeze-thaw cycles), and $10.83 \%$ (75 freeze-thaw cycles). Micropores and cracks gradually develop with increasing freeze-thaw cycles. Various hydration products can be identified in porous areas by high-magnification hydration cement paste. Generally speaking, large crystals of calcium hydroxide, slender needle-like calcium vanadium stone, and fine fibrous aggregates of calcium silicate hydrate can be observed under a 5,000- 


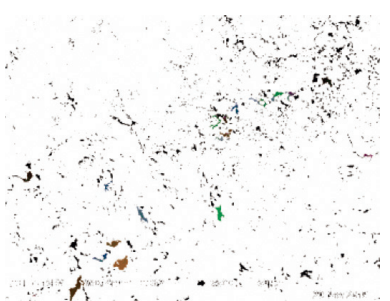

(a)

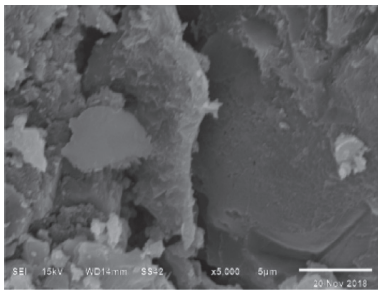

(e)

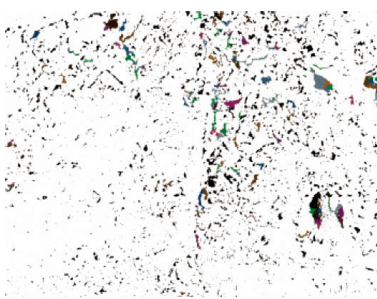

(b)

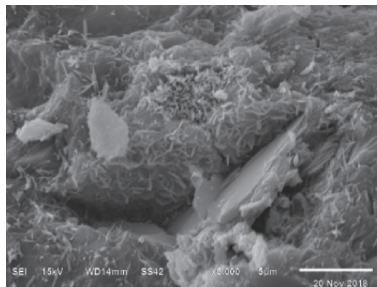

(f)

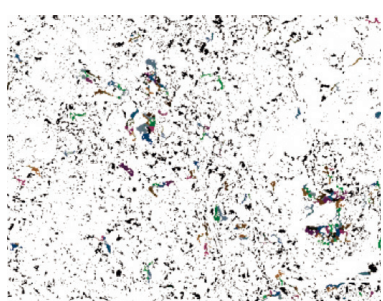

(c)

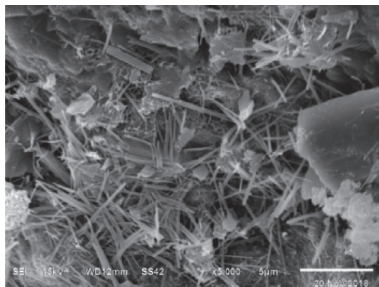

(g)

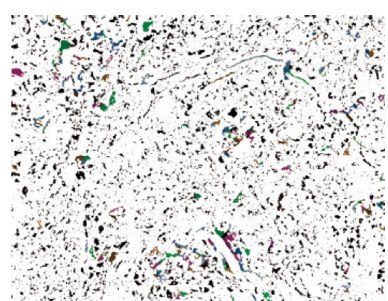

(d)

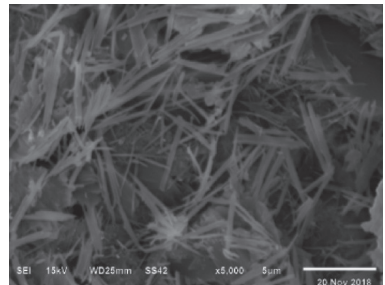

(h)

Figure 2: Micropore structure of hydrated cement paste (SEM 500X; SEM 5000X): (a) SEM 500X binary diagram for FTC00; (b) SEM 500X binary diagram for FTC25; (c) SEM 500X binary diagram for FTC50; (d) SEM 500X binary diagram for FTC75; (e) SEM 5000X diagram for FTC00; (f) SEM 5000X diagram for FTC25; (g) SEM 5000X diagram for FTC50; (h) SEM 5000X diagram for FTC75.

fold microscope. Calcium silicate hydrate phase (C-S-H) accounts for about $55 \%$ of the volume of hydrated cement paste and is the main source of its long-term strength and durability. Its morphology may be fibrous and reticular. Figures $2(\mathrm{e})-2(\mathrm{~h})$ show an aggregate of hydrated calcium silicate in hydrated cement paste enlarged 5,000 times. The picture shows that this obviously increases with increasing freeze-thaw cycles.

3.2. Quasistatic Stress-Strain Relationship. Eight groups of $100 \times 100 \times 100 \mathrm{~mm}$ specimens were poured for this paper. After 28 days in a standard maintenance room, freeze-thaw cycles were tested by the slow freezing method, with 0,25 , 50 , and 75 freeze-thaw cycles. The quasistatic test of uniaxial compression was carried out on a microcomputer-controlled universal testing machine. The complete stress-strain curve of concrete under uniaxial compression was measured by displacement loading with a loading rate of $1 \mathrm{~mm} / \mathrm{min}$. Data processing was carried out according to the relevant requirements of the standard test method for mechanical properties of ordinary concrete. The strength value measured for $100 \times 100 \times 100 \mathrm{~mm}$ specimens was multiplied by the dimension-conversion coefficient of 0.95 [13]. In the quasistatic splitting tensile test, the displacement control mode was selected for loading control, and the loading rate was $0.1 \mathrm{~mm} / \mathrm{min}$. The splitting tensile strength measured for $100 \times 100 \times 100 \mathrm{~mm}$ specimens was multiplied by the dimension-conversion coefficient of 0.85 [13].

Figure 3(a) shows the complete stress-strain curve of concrete under uniaxial compression after different freezethaw cycles. As the number of freeze-thaw cycles increased, the peak stress of the concrete decreased, the peak strain increased, the number of internal microcracks and pores increased, and the pore size increased. The peak stress of the concrete under uniaxial compression decreased, and the peak strain increased. Figure 3(b) shows the split tensile stress-strain complete curve of concrete after freeze-thaw cycles. The test results show that the peak stress of concrete decreases gradually with increasing numbers of freeze-thaw cycles, while the peak strain corresponding to the peak stress increases gradually. The quasistatic stress-strain curves obtained in this paper vary with the number of freeze-thaw cycles [8-10]. The peak stress and peak strain values of the typical stress-strain curves of each group are shown in Table 1.

\subsection{Calibration of Concrete Damage Plasticity Model}

3.3.1. Concrete Damage Plasticity Model. The Concrete Damage Plasticity (CDP) model in ABAQUS deals with plastic behavior, compressive behavior, tensile behavior, confinement, and damage mechanism of concrete and has the potential to converge the results to accuracy as compared with other models [18]. The model assumed that the main two concrete failure mechanisms are the tensile cracking and compression crushing of the concrete material. The model involves the combination of nonassociated multihardening plasticity and isotropic scalar damaged elasticity to describe the irreversible damage that occurs during the fracturing process.

One of the advantages of the CDP model is that uniaxial test data can be extended to three-dimensional data by ABAQUS program, and then finite element analysis can be performed. The damage in snow-melting heated pavement concrete was simulated based on the CDP model with experiment parameters [19]. The calibrated CDP model in ABAQUS was used to predict the responses of HFRC materials and structural members subjected to shear and seismic loads [20]. Fourteen (group) parameter values were required for finite analysis based on the CDP constitutive model, while plasticity parameters and stiffness recovery factors have the default values [21] for ordinary concrete 


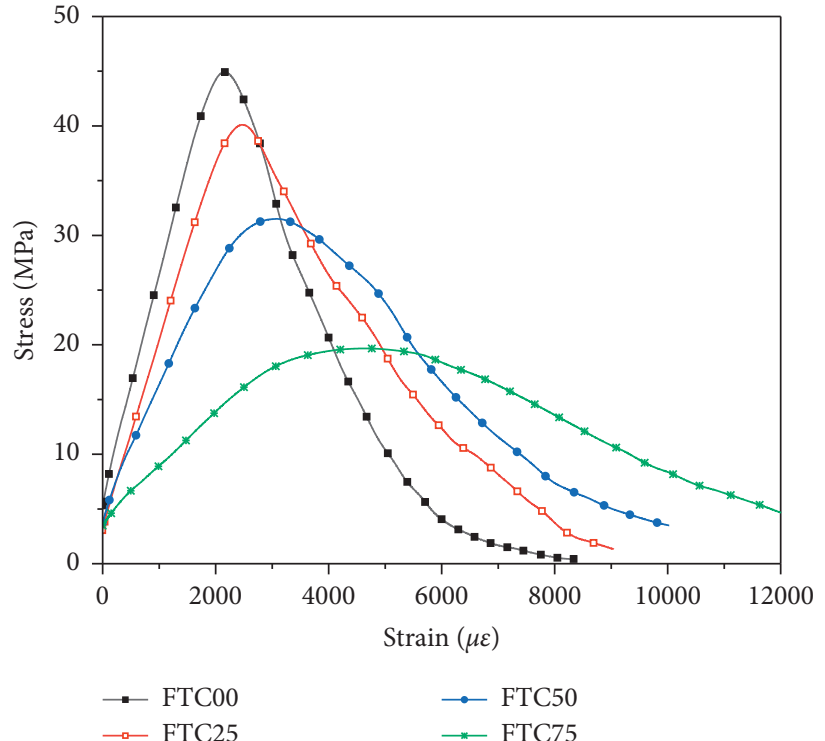

(a)

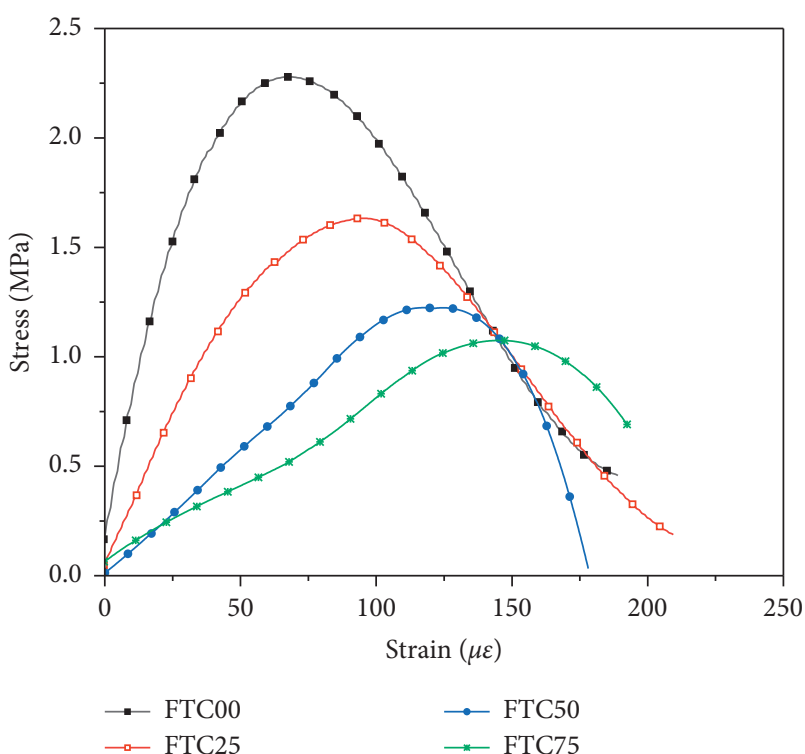

(b)

Figure 3: Complete compressive and split tensile stress-strain full curve of concrete after freeze-thaw influence: (a) uniaxial compression; (b) split tensile.

Table 1: Static compression and split tensile data of concrete after different numbers of freezing-thaw cycles.

\begin{tabular}{lccccc}
\hline Number of freeze-thaw cycles & $E(\mathrm{GPa})$ & $f_{\mathrm{cm}}(\mathrm{MPa})$ & $\mathcal{E}_{\mathrm{cm}}\left(10^{-6}\right)$ & $F_{\mathrm{tsm}}(\mathrm{MPa})$ & $\varepsilon_{\mathrm{tsm}}\left(10^{-6}\right)$ \\
\hline 0 & 30.7 & 44.93 & 2150.3 & 2.27 & 1.63 .75 \\
25 & 21.6 & 40.10 & 2482.0 & 95.07 \\
50 & 18.9 & 31.57 & 3095.0 & 1.22 & 119.1 \\
75 & 10.2 & 19.67 & 4696.7 & 1.07 & 146.2 \\
\hline
\end{tabular}

Note. $E$ is the initial elastic modulus, $f_{\mathrm{cm}}$ is the peak stress, $\varepsilon_{\mathrm{cm}}$ is the strain at peak stress, $F_{\mathrm{tsm}}$ is the peak split tensile strength, and $\varepsilon_{\mathrm{tsm}}$ is the corresponding strain for peak split tensile strength.

(Table 2). And Table 3 shows the basic parameters of concrete under different freezing-thawing cycles.

\subsubsection{Uniaxial Tension and Compression Behavior of} Concrete. The stress-strain evolution of concrete materials was controlled by tensile equivalent plastic strain and compressive equivalent plastic strain, respectively [22], as shown in Figure 4.

The inelastic strain (cracking strain) in uniaxial compression (tension) can be calculated by

$$
\left\{\begin{array}{l}
\varepsilon_{t}^{\mathrm{ck}}=\varepsilon_{t}-\varepsilon_{o t}^{e l}=\varepsilon_{t}-\frac{\sigma_{t}}{E_{0}}, \\
\varepsilon_{c}^{\mathrm{in}}=\varepsilon_{c}-\varepsilon_{o c}^{e l}=\varepsilon_{c}-\frac{\sigma_{c}}{E_{0}} .
\end{array}\right.
$$

The damage factors can be calculated by the scaled strain method [23]:

$$
\left\{\begin{array}{l}
d_{t}=1-\frac{\sigma_{t} E_{0}^{-1}}{\varepsilon_{t}^{p l}\left(1 / b_{t}-1\right)+\sigma_{t} E_{0}^{-1}} \\
d_{c}=1-\frac{\sigma_{c} E_{0}^{-1}}{\varepsilon_{c}^{p l}\left(1 / b_{c}-1\right)+\sigma_{c} E_{0}^{-1}}
\end{array}\right.
$$

where $d_{t}$ and $d_{c}$ are constants. Reinhardt and Cornelissen [24] suggested that the value of $d_{t}$ should be 0.1 ; Sinha et al. [25] suggested that $d_{c}$ should be 0.7 .

According to formula (1), the cracking (inelastic) strain under different freezing-thawing cycles can be calculated. The relationship between yield stress and cracking strain of uniaxial tensile behavior is shown in Table 4 .

\subsection{Finite Element Analysis of Quasistatic Axial Compression}

3.4.1. Mesh Convergence Study. All the concrete specimens were modeled by 20 -node hexahedron quadratic reduction integral elements (C3D20R) [26]. Mesh convergence study was carried out with three mesh sizes, $4 \mathrm{~mm}, 2 \mathrm{~mm}$, and $1 \mathrm{~mm}$. It was found that the mesh of $2 \mathrm{~mm}$ led to relatively accurate results for the notched concrete beam in ABAQUS example.

3.4.2. Failure Pattern of Cube Specimen. The failure process of a concrete cube specimen under quasistatic loading can be described as follows [27]: compression deformation occurs vertically and tension deformation occurs horizontally after loading. With an increased load, the stress of specimens 
TABLE 2: Parameters (plasticity and stiffness recovery) of concrete in the CDP model.

\begin{tabular}{lccccccc}
\hline Dilation angle $\left(^{\circ}\right)$ & Eccentricity & $f_{b 0} / f_{c 0}$ & $K$ & Viscosity Parameter & Tension recovery & Compression recovery \\
\hline 30 & 0.1 & 1.16 & 0.667 & 0.0005 & 0 & 1 \\
\hline
\end{tabular}

TABle 3: Parameters (density, modulus of elasticity, and Poisson's ratio) of concrete in the CDP model.

\begin{tabular}{lccc}
\hline Number of freeze-thaw cycles & Density $\left(\mathrm{kg} / \mathrm{m}^{3}\right)$ & Modulus of elasticity $(\mathrm{GPa})$ & Poisson's ratio \\
\hline 0 & 2434 & 30.7 & 0.2 \\
25 & 2430 & 21.6 & 0.2 \\
50 & 2427 & 18.9 & 0.2 \\
75 & 2423 & 10.2 & 0.2 \\
\hline
\end{tabular}

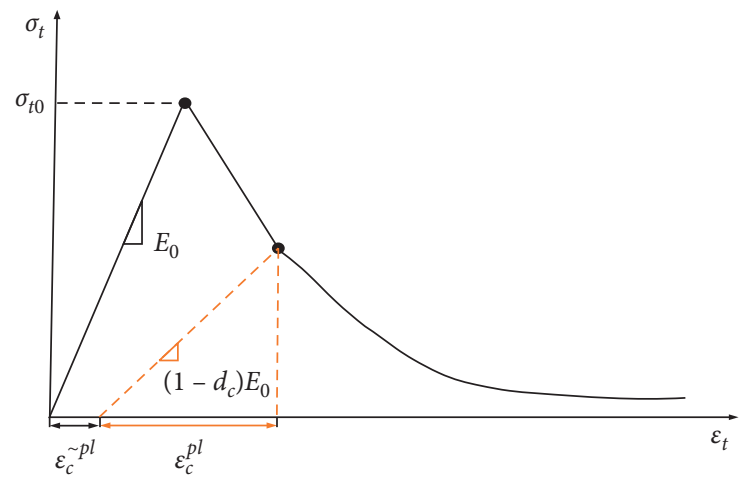

(a)

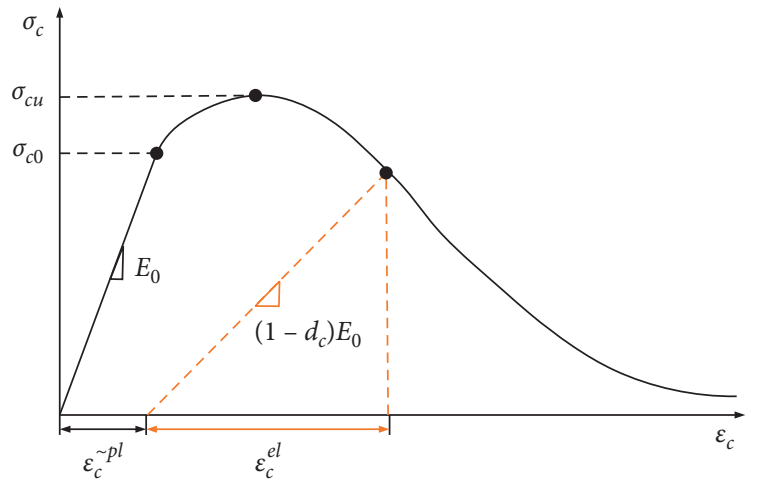

(b)

Figure 4: Response of concrete to uniaxial loading in tension and compression: (a) tension data; (b) compressive data [22].

TABLE 4: Data of yield stress and cracking strain of uniaxial tensile behavior for the CDP model.

\begin{tabular}{|c|c|c|c|c|c|c|c|}
\hline \multicolumn{2}{|c|}{ FTC00 } & \multicolumn{2}{|c|}{ FTC25 } & \multicolumn{2}{|c|}{ FTC50 } & \multicolumn{2}{|c|}{ FTC75 } \\
\hline $\begin{array}{l}\text { Yield stress } \\
(\mathrm{MPa})\end{array}$ & $\begin{array}{c}\text { Cracking strain } \\
(\mu \varepsilon)\end{array}$ & $\begin{array}{l}\text { Yield stress } \\
(\mathrm{MPa})\end{array}$ & $\begin{array}{c}\text { Cracking strain } \\
(\mu \varepsilon)\end{array}$ & $\begin{array}{l}\text { Yield stress } \\
(\mathrm{MPa})\end{array}$ & $\begin{array}{c}\text { Cracking strain } \\
(\mu \varepsilon)\end{array}$ & $\begin{array}{c}\text { Yield stress } \\
(\mathrm{MPa})\end{array}$ & $\begin{array}{c}\text { Cracking strain } \\
(\mu \varepsilon)\end{array}$ \\
\hline 1.82 & 0.00 & 1.30 & 0.00 & 0.98 & 0.00 & 0.86 & 0.00 \\
\hline 2.05 & 0.95 & 1.47 & 3.25 & 1.10 & 6.36 & 0.96 & 5.22 \\
\hline 2.27 & 9.80 & 1.63 & 16.13 & 1.22 & 24.75 & 1.07 & 25.25 \\
\hline 2.04 & 35.58 & 1.47 & 58.18 & 1.10 & 98.03 & 0.96 & 135.75 \\
\hline 1.81 & 56.61 & 1.30 & 93.58 & 0.98 & 164.64 & 0.86 & 241.57 \\
\hline 1.59 & 79.50 & 1.14 & 134.98 & 0.85 & 249.11 & 0.75 & 380.29 \\
\hline 0.90 & 190.13 & 0.81 & 262.72 & 0.73 & 366.81 & 0.64 & 578.65 \\
\hline 1.82 & 0.00 & 1.30 & 0.00 & 0.98 & 0.00 & 0.86 & 0.00 \\
\hline
\end{tabular}

increases and the four vertical edges bear nearly uniaxial compression, while the internal points show triaxial compression, sometimes with tensile stress. When the specimen approaches failure, vertical cracks appear at the center of the specimen height and near the side surface and then extend upward and downward, gradually turning to the corner of the specimen to form an octagonal crack symmetrically connected upside-down. As the load increases, new octagonal cracks expand from the surface to the interior, and the middle concrete bulges outward and begins to peel off, eventually becoming a quadrangular pyramid failure mode [28] connected upside-down, as shown in Figure 5.

Figure 6 shows the vertical stress $\left(\sigma_{\text {yy }}\right)$, maximum elongation tensile strain $\left(\varepsilon_{1}\right)$, and maximum plastic strain nephograms of concrete without freeze-thaw cycles and concrete with 50 freeze-thaw cycles analyzed by CDP model parameters. With an increased load, the maximum tensile stress in concrete reaches the maximum value. Part of the concrete peels off and finally forms a quadrangular pyramid failure mode. 


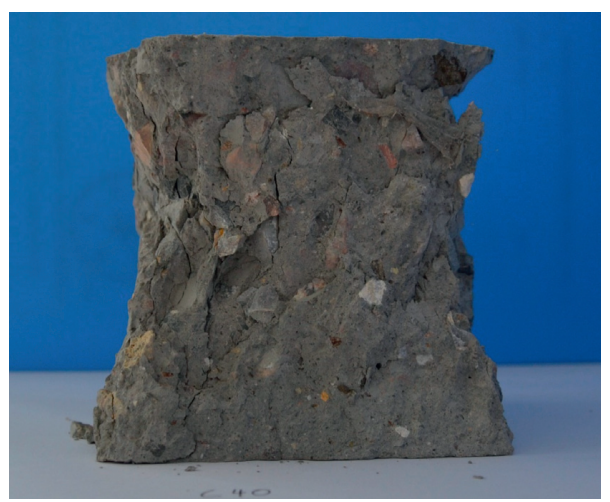

Figure 5: Axial compression failure mode image of concrete.

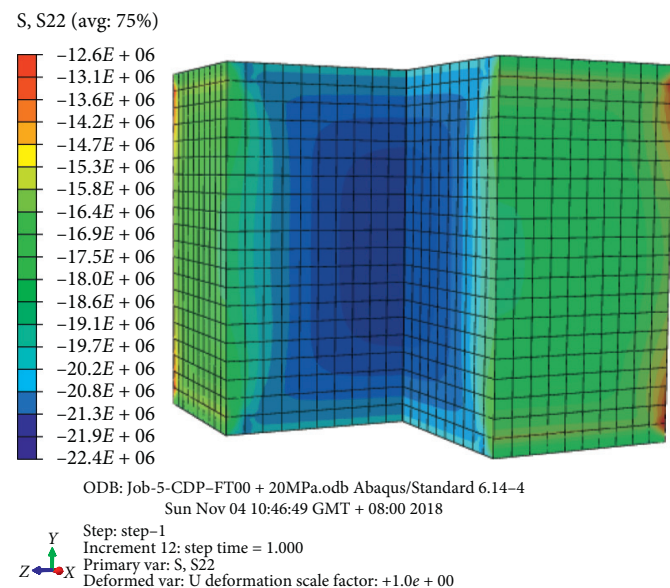

(a)

NE, Max. principal (avg: $75 \%$ )

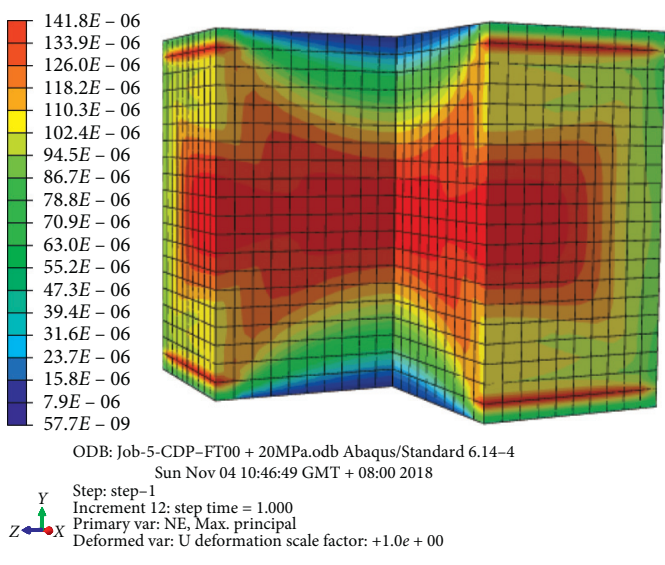

(c)

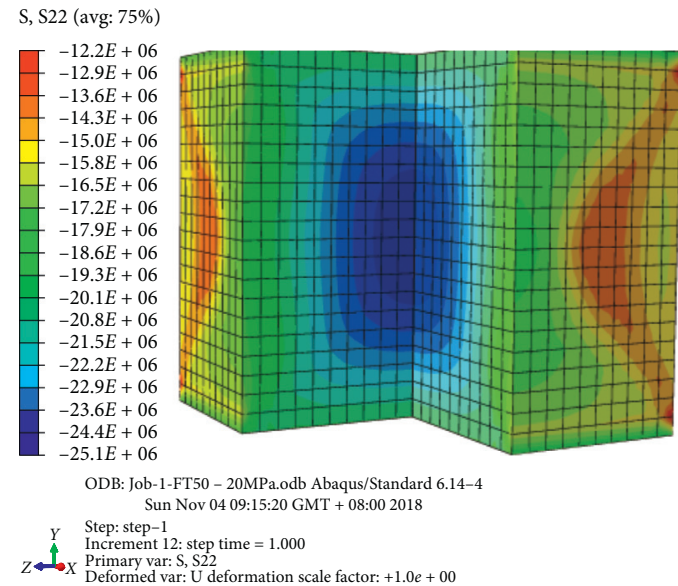

(b)

NE, Max. principal (avg: 75\%)

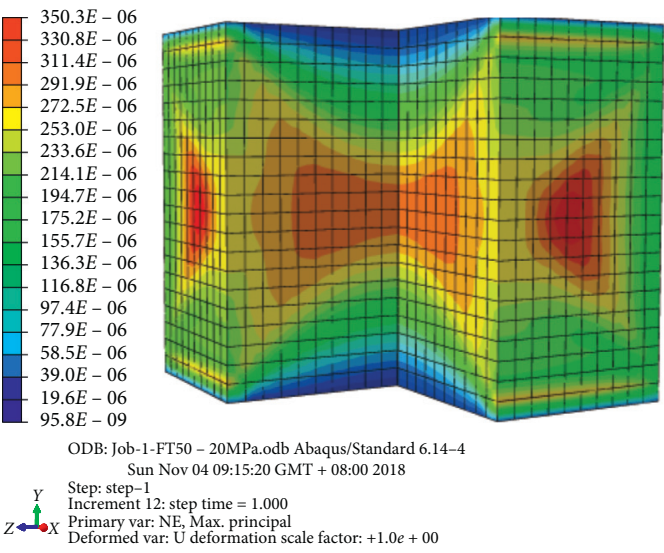

(d)

FIgURE 6: Continued. 


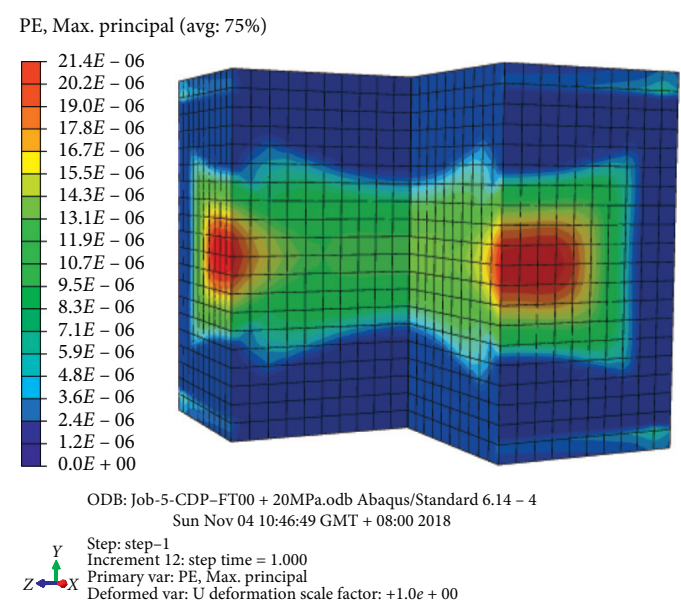

(e)

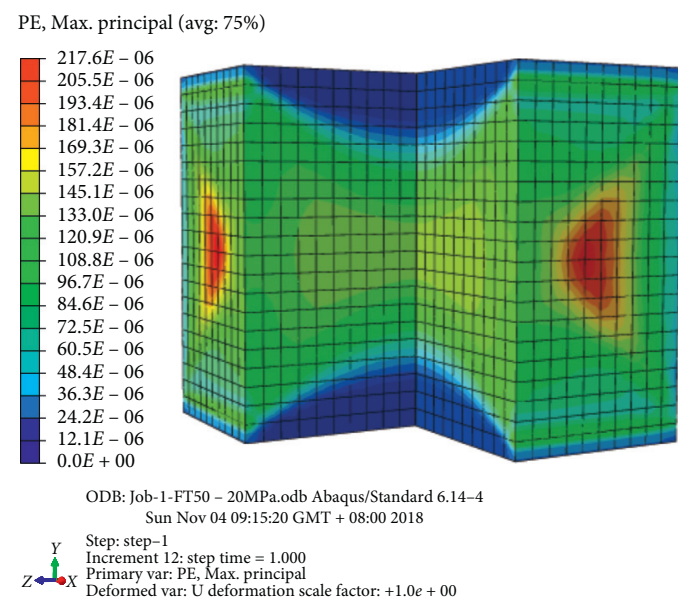

(f)

Figure 6: Stress nephograms of concrete analyzed by the CDP constitutive model: (a) vertical stress nephogram $(P=20 \mathrm{MPa}$ FTC00); (b) vertical stress nephogram $(P=20 \mathrm{MPa}$ FTC50); (c) maximum principal stress nephogram $(P=20 \mathrm{MPa}$ FTC00); (d) maximum principal stress nephogram $(P=20 \mathrm{MPa}$ FTC50); (e) maximum plastic strain nephogram $(P=20 \mathrm{MPa}$ FTC00); (f) maximum plastic strain nephogram $(P=20 \mathrm{MPa}$ FTC50).

PEEQ (avg: 75\%)

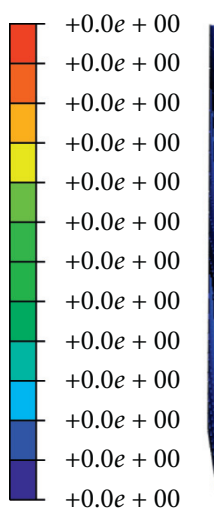

ODB: Job-6-CDP-FTC00.odb Abaqus/Standard 6.14-4 Sun Feb 08 14:15:39 GMT-00:00 2020

Step: step-1

Increment 12: step time $=1.000$

$Z \omega_{X}$ Primary var: PEEQ

Deformed var: $\mathrm{U}$ deformation scale factor: $+1.0 e+00$
PEEQ (avg: 75\%)

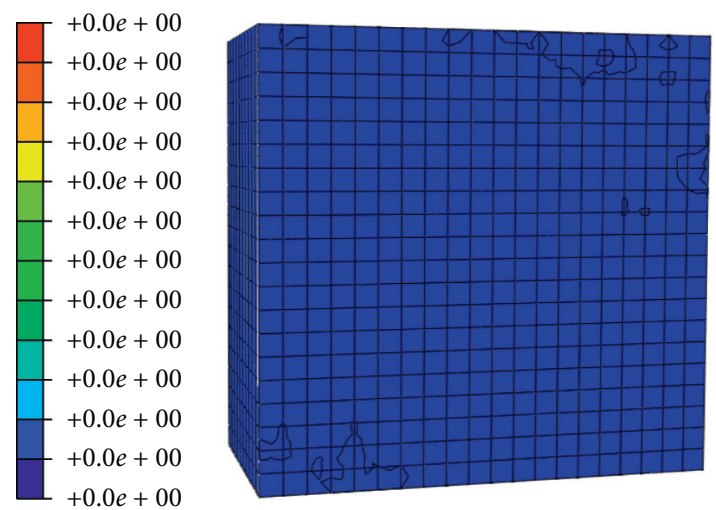

ODB: Job-7-CDP-FTC25.odb Abaqus/Standard 6.14-4 Sun Feb 08 14:35:23 GMT-00:00 2020

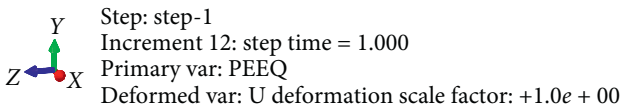

(b)

FIgURE 7: Continued. 


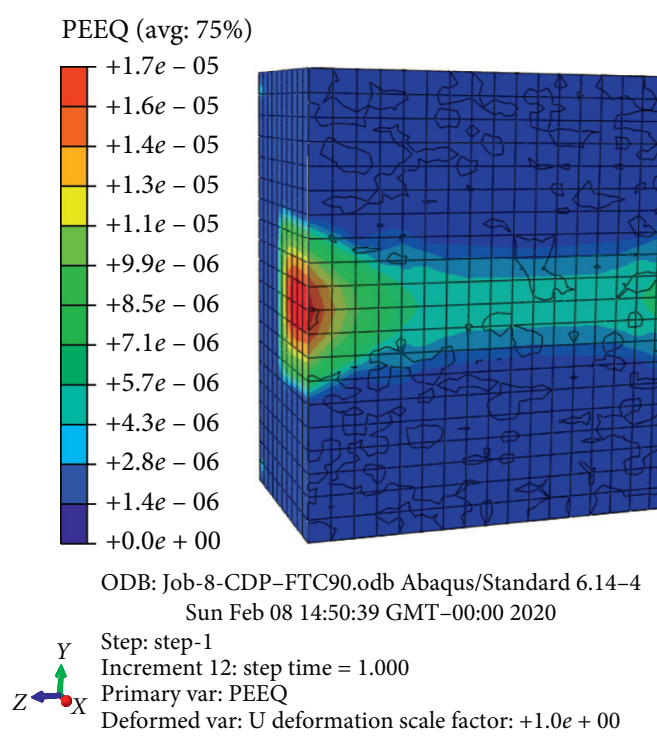

(c)

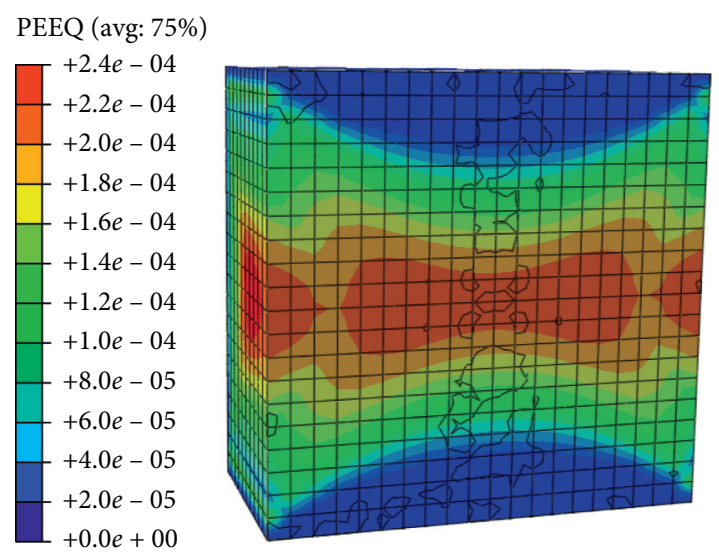

ODB: Job-9-CDP-FTC75.odb Abaqus/Standard 6.14-4 Sun Feb 08 15:13:39 GMT-00:00 2020 $\begin{array}{ll}Y & \text { Step: step-1 } \\ \text { Increment 12: step time }=1.000 \\ \text { Primary var: PEEQ }\end{array}$

Deformed var: $\mathrm{U}$ deformation scale factor: $+1.0 e+00$

(d)

FIGURE 7: Equivalent plastic strain nephogram for freeze-thaw concrete: (a) FTC00; (b) FTC25; (c) FTC50; (d) FTC75.

3.4.3. Equivalent Plastic Strain for Concrete after FreezeThaw Cycles. Figure 7 shows the equivalent plastic strain nephogram for freeze-thaw concrete in the load of $12 \mathrm{kN}$. The equivalent plastic strain can show the failure morphology of the sample. When the value of equivalent plastic strain was greater than zero, the concrete material yields and plastic strain occurs in the specimen. It can be seen that the value and range of equivalent plastic strain were positively correlated with the number of freezing-thawing cycles.

\section{Conclusions}

The uniaxial tension and compression testes were carried out on concrete specimens with different numbers of freezethaw cycles. SEM images and macromechanical properties were used to study the damage of concrete due to freezethaw cycling. The stress-strain curves under uniaxial compression and splitting tensile were discussed. The parameters of the CDP constitutive model were calibrated by freezethaw test curve. It is also found that the CDP model in ABAQUS was able to simulate the strain and failure mode of concrete specimens under uniaxial compression and tension.

\section{Data Availability}

All experimental data, models, and code generated or used during the study are available from the corresponding author upon request.

\section{Conflicts of Interest}

The authors declare that there are no conflicts of interest regarding the publication of this paper.

\section{Acknowledgments}

The research reported in this paper was sponsored by the Science and Technology Project of Qinghai Province, PRC (nos. 2016-ZJ-721 and 2018-ZJ-T01). This study was also supported by the Research on Lifetime Design and Application of Concrete Bridges in Gansu Highway, which was sponsored by the Gansu Province Department of Transportation.

\section{References}

[1] M. A. Hariri-Ardebili, L. Sanchez, and R. Rezakhani, "Aging of concrete structures and infrastructures: causes, consequences, and cures (C3)," Advances in Materials Science and Engineering, vol. 2020, Article ID 9370591, 3 pages, 2020.

[2] P. K. Mehta and J. M.Monteiro Paulo, Concrete: Microstructure, Properties, and Materials, pp. 135-139, McGrawHill, New York, NY, USA, 3rd edition, 2006.

[3] T. C. Power, The Physical Structure and Engineering Properties of Concrete, Bulletin 90, Portland Cement Association, Skokie, IL, USA, 1958.

[4] T. Akçaoğlu, M. Tokyay, and T. Çelik, "Assessing the ITZ microcracking via scanning electron microscope and its effect on the failure behavior of concrete," Cement and Concrete Research, vol. 35, no. 2, pp. 358-363, 2005.

[5] T. Oesch, T. Oesch, E. Landis, E. Landis, D. Kuchma, and D. Kuchma, "A methodology for quantifying the impact of casting procedure on anisotropy in fiber-reinforced concrete using X-ray CT," Materials and Structures, vol. 51, no. 3, pp. 1-13, 2018.

[6] Y. Komizo and H. Terasaki, "In situtime resolved X-ray diffraction using synchrotron," Science and Technology of Welding and Joining, vol. 16, no. 1, pp. 79-86, 2011.

[7] W. Tian, X. Li, and F. Wang, "Experimental study on seterioration mechanism of concrete under freeze thaw cycles coupled with sulfate solution," Chinese Ceramic Society, vol. 38, no. 3, pp. 702-710, 2019. 
[8] Y. Guo, C. Zhai, P. Li, and A. Shen, "Influence mechanism of frost resistance and microstructure of road concrete," Journal of Chongqing Jiaotong University, vol. 37, no. 6, pp. 48-55, 2018.

[9] X. Yang, G. Wang, S. Gao, M. Song, and A. Wang, "Equation for the degradation of uniaxial compression stress of concrete due to freeze-thaw damage," Advances in Materials Science and Engineering, vol. 2019, Article ID 8603065, 8 pages, 2019, https://www.hindawi.com/journals/amse/2019/8603065/.

[10] L. Jiang and D. Niu, "Study on constitutive relation of concrete under sulfate attack and freeze-thaw environment," Journal of Sichuan University, vol. 48, no. 3, pp. 71-78, 2016.

[11] J. Wang, D. Niu, and B. Yuan, "Constitutive relation and microstructure on shotcrete after freeze and thaw damage," Journal of Civil Engineering, Environment and Architecture, vol. 38, no. 1, pp. 30-39, 2016.

[12] A. Duan, W. Jin, and J. Qian, "Effect of freeze-thaw cycles on the stress-strain curves of unconfined and confined concrete," Materials and Structures, vol. 44, no. 7, pp. 1309-1324, 2011.

[13] China Academy of Building Research, Standard Test Method for Long-Term Performance and Durability of Ordinary Concrete GB/T50082-2009, China Architecture \& Building Press, Beijing, China, 2010.

[14] B. Zhang, Concrete and Mortar Mixing Ratio Manual, Tianjin University Press, Tiasnjin, China, 2012.

[15] China Academy of Building Research, Standard Test Method for Mechanical Properties of Ordinary Concrete GB/T 500812002, China Architecture \& Building Press, Beijing, China, 2004.

[16] C. Liu, B. Shi, J. Zhou, and C. Tang, "Quantification and characterization of microporosity by image processing, geometric measurement and statistical methods: Application on SEM images of clay materials," Applied Clay Science, vol. 54, no. 1, pp. 97-106, 2011.

[17] C. Liu, C.-S. Tang, B. Shi, and W.-B. Suo, "Automatic quantification of crack patterns by image processing," Computers \& Geosciences, vol. 57, no. 4, pp. 77-80, 2013.

[18] A. Raza, Q. U. Z. Khan, and A. Ahmad, "Numerical investigation of load-carrying capacity of GFRP-reinforced rectangular concrete members using CDP model in abaqus," Advances in Civil Engineering, vol. 2019, pp. 1-21, 2019.

[19] K. Liu, H. Xie, C. Jin, S. Huang, and F. Wang, "The equivalent plasticity strain analysis of snow-melting heated pavement concrete exposed to inner elevated temperatures," Construction and Building Materials, vol. 137, pp. 66-75, 2017.

[20] L. Xu, B. Li, Y. Chi, C. Li, B. Huang, and Y. Shi, "Stress-strain relation of steel-polypropylene-blended fiber-reinforced concrete under uniaxial cyclic compression," Advances in Materials Science and Engineering, vol. 2018, pp. 1-19, 2018.

[21] ABAQUS User's Manual Volume III Materials. 6.10-EF..

[22] G. H. Mahmud, Z. Yang, and A. M. T. Hassan, "Experimental and numerical studies of size effects of ultra high performance steel fibre reinforced concrete (UHPFRC) beams," Construction and Building Materials, vol. 48, pp. 1027-1034, 2013.

[23] V. Birtel and P. Mark, "Parameterised finite element modelling of rc beam shear failure," in Proceedings of the Abaqus Users' Conference, Hermès Science, Boston, MA, USA, pp. 95-108, May 2006.

[24] H. W. Reinhardt and H. A. W. Cornelissen, "Post-peak cyclic behaviour of concrete in uniaxial tensile and alternating tensile and compressive loading," Cement and Concrete Research, vol. 14, no. 2, pp. 263-270, 1984.
[25] B. P. Sinha, K. H. Gerstle, and L. G. Tulin, "Stress-strain relations for concrete under cyclic loading," Journal of the ACI, vol. 61, no. 2, pp. 195-211, 1964.

[26] P. Zeng, Finite Element Analysis and Application, Tsinghua University Press, vol. 50, no. 2, pp. 294-295, Beijing, China, 2004.

[27] Z. Lu, Elasto-plastic Analysis of Buildings against Earthquake, pp. 152-153, China Building Industry Press, Beijing, China, 2015.

[28] Z. Guo, Principles of Reinforced Concrete, Butterworth Heinemann, Oxford, MS, USA, 2014. 